\title{
ABD Dolarının Emtia Fiyatları Üzerindeki Etkisinin İncelenmesi
}

\section{The Impact of the US Dollar's Movements on Commodity Prices}

\author{
Önder BÜBERKÖKÜ'
}

\begin{abstract}
ÖZET
Bu çalışmada emtia piyasalarındaki fiyat hareketlerinin açıklanmasında ABD dolarının küresel bazdaki değeri üzerinde durulmuştur. $A B D$ dolarını temsilen geniş tanımlı reel efektif ABD dolar endeksi (Broad dollar index) kullanılmıştır. Emtia olarak IMF tarafından yayınlanan gıda, içecek, metal, yakıt, petrol ve tarımsal emtia fiyat endeksleri kullanılmıştır. Değişkenler arasındaki uzun dönemli ilişki analizinde Johansen (1988) koentagrasyon testi ile Maki (2012) çoklu yapısal kırılmalı koentegrasyon testinden yararlanılmıştır. Çalışmada kullanılan serilerin ve modellerin yapısal değişimler içerip içermediği ise Bai ve Perron $(1998,2003)$ testi ile incelenmiştir. Serilerin durağanlık özelliklerinin incelenmesinde ise Carrion-i Silvestre vd. (2009) çoklu yapısal kırılmalı birim kök testinden yararlanılmıştır. Kısa dönemli ilişki analizinde ise Hatemi-J (2012) tarafından geliştirilen asimetrik nedensellik testi kullanılmıştır. Çalışma bulguları ABD doları ile gıda, yakıt ve petrol emtiaları arasında ters yönlü uzun dönemli bir ilişki olduğuna işaret etmektedir. Uzun dönemde ABD dolarının \%1 değer kazanmasının ilgili emtiaların fiyatında sırasıyla \%0.44, \%1 ve \%1.3'lük bir azalışa yol açtığı görülmektedir. ABD doları ile metal, içecek ve tarımsal emtia endeksleri arasında ise herhangi bir uzun dönemli ilişkiye rastlanmamıştır. Kısa dönemli ilişki analizi sonuçlarına bakıldığında ise Hatemi-J (2012) asimetrik nedensellik testi sonuçlarına göre ABD dolarının değer kaybetmesi sadece yakıt, ham petrol ve tarımsal emtia fiyatlarının yükselmesine yol açarken ABD dolarının değer kazanması inceleme kapsamındaki tüm emtiaların fiyatlarının düşmesine yol açmaktadır. Dolayısıyla, kısa dönemde ABD dolarının değer kaybetmesinden ziyade değer kazanmasının emtia fiyatları üzerinde daha fazla etkili olduğu anlaşılmaktadır.
\end{abstract}

Anahtar kelimeler : ABD Doları, Emtia Fiyatları, Çoklu yapısal kırılmalar, Asimetriknedensellik testi

\begin{abstract}
In this study both the long- and short-term impacts of the US dollar's exchange rate movements on commodity prices are examined. Commodities such as food (including cereal, vegetable oils, meat, seafood, sugar, and fruit), beverages (including coffee, tea, and cocoa), metals (including aluminium, iron ore, tin, nickel, zinc, lead, and uranium), fuel energy (including crude oil, natural gas, and coal), crude oil (including simple avareges of Brent, WTI and Dubai fateh) and agriculture (including timber, cotton, wool rubber, and hides) are considered. The longterm impact of the US dollar on commodity prices is investigated using Maki's (2012) cointegration test, which allows multiple regime shifts, and the short-term effect is examined using Hatemi-J's (2012) asymmetric causality test. Furthermore, in order to determine the integration order of the series, Carrion-i Silvestre et al.'s (2009) unit root test with multiple structural breaks is used, and Bai and Perron's (1998, 2003) test is applied to determine whether or not models have regime shifts. Results show that there is an inverse long-term relationship between the US dollar and food, fuel, and energy commodity prices. In other words, an increase in the US dollar causes a decrease in the price of food, fuel, and crude oil commodities in the long run. And it is observed that this effect is more dominant especially in fuel and crude oil commodity prices. Additionally, asymmetric causality test results show that US dollar appreciation causes a decrease in all commodity prices under investigation, however US dollar depreciation causes an increase only in the price of fuel, crude oil, and agricultural commodities. This means that in the short run the impact the appreciating dollar has on commodity prices is stronger than that of the depreciating dollar.
\end{abstract}

Keywords : US Dollar, Commodity prices, Multiple structural breaks, Asymmetric causality test 


\section{GíRiş}

Güncel gelişmelere bakıldığında emtia piyasalarında önemli fiyat hareketlerinin yaşandığı görülmektedir. Emtia piyasalarındaki bu fiyat hareketlerine nelerin yol açtığı konusundaki tartışmalara bakıldığında ise genel olarak Çin gibi yükselen piyasa ekonomilerinin talep yapısındaki değişimler, artan spekülatif işlemler, küresel bazda değişen likidite düzeyi, ABD dolarının küresel bazdaki değeri gibi faktörlerin öne çıktığı görülmektedir (Fan ve $\mathrm{Xu}, 2011)$. Bu çalışmada emtia fiyatları üzerinde ABD dolarının etkisi üzerinde durulmuştur. Öncelikle gerek uluslararası literatürdeki çalışmalarda (Lim, 2006; Akram, 2008; Druck, vd., 2015, Chen vd., 2016; Truchis ve Keddad, 2016; Lin vd., 2016; Nazlioglu ve Soytaş, 2012; Sari, vd., 2010; Reboredo ve Ugando, 2014) gerekse saygın uluslararası finansal kuruluşlarca yayınlanan raporlarda belirtildiği gibi emtialar önemli oranda $A B D$ doları cinsinden ticarete konu olmaktadır. Örneğin, IMF'nin 2008 yılı Dünya Ekonomik Görünümü adlı raporunda emtiaların yoğun bir şekilde $A B D$ doları ile ticarete konu oldukları belirtildikten sonra yapılan bir analizde $A B D$ dolarındaki değişimlerin enerji, gıda, tarım ve metal emtia fiyatları üzerinde etkili olduğu sonucuna ulaşılmıştır. Dolayısıyla ABD doları ile emtia fiyatları arasındaki ilişki hem literatürde hem de pratik hayatta oldukça ilgi çeken bir konudur. ABD dolarının değeri ile emtia fiyatları arasındaki teorik ilişki ise literatürde genelde iki yaklaşım ile açıklanmaktadır. Bunlardan ilki tek fiyat kanununa bağlı olarak satın alma gücü paritesi yaklaşımıdır. Bu yaklaşıma göre emtialar daha çok $A B D$ doları cinsinden ticarete konu olmaktadırlar. Bu kapsamda ABD dolarında meydana gelen değişimler diğer ülkelerin yerel para birimlerinin satın alma gücünü etkilemektedir. Buna bağlı olarak da emtiaların arz ve talep dengesi değişmekte bu da emtia fiyatlarında değişime yol açmaktadır (Blomberg ve Haris,1995; Golup, 1983; Krugman, 1983 ; Hussein vd., 2017; Reboredo ve Ugando,2014; Hamilton, 2008; Truchis ve Keddad, 2016; Jiang ve Gu, 2016).

$\mathrm{Bu}$ durum dolar ile ticarete konu olan tüm emtialar için geçerli olmakla birlikte petrol özelinde Şekil 1'de gösterildiği gibi açıklanabilir (Trehan, 1986, s. 26). Burada $D_{0}$ net bazda petrol ithal eden ülkelerin toplam petrol talebini, $\mathrm{S}_{0}$ ise net bazda petrol arz eden ülkelerin toplam petrol arzını ifade ederken $P_{0 \$}$ bu arz ve talep düzeylerine bağlı olarak küresel piyasalarda oluşan dünya petrol fiyatını göstermektedir. Diğer unsurların yanı sıra petrolün $A B D$ doları cinsinden değeri sabit iken, örneğin FED kararlarına bağlı olarak, ABD dolarının küresel bazda değer kaybettiği bir ortamda net baz bazda petrol ithal eden ülkelerin kendi para birimleri cinsinden petrol fiyatı azalacağından bu ülkelerin petrol talepleri artacaktır.

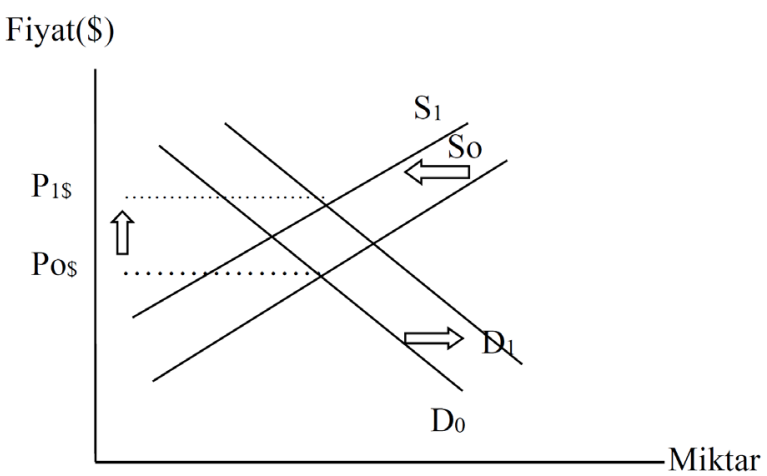

Şekil 1: ABD dolarındaki değişimlerin petrol fiyatı üzerindeki etkisi

Bu da talep eğrisinin $D_{0}$ 'dan $D_{1}$ e kaymasına yol açacaktır. Dolayısıyla, küresel petrol fiyatı değişmez iken doların küresel bazda değer kaybetmesi ve petrolün dolar cinsinden ticarete konu olmasına bağlı olarak küresel bazda petrol talebi artmış olacaktır. Arz tarafına gelince diğer unsurların yanı sıra petrolün $A B D$ doları cinsinden değeri değişmez iken $A B D$ dolarının küresel bazda değer kaybı petrol arzını da etkileyecektir. Çünkü, bu durumda net bazda petrol inraç eden ülkelerin firmalarının kendi para birimleri cinsinden petrol gelirleri düşmüş olacaktır. Bu da arz eğrisinin $\mathrm{S}_{0}^{\prime}$ dan $\mathrm{S}_{1}$ 'e kaymasına yol açacaktır. Böylece doların küresel bazda değer kaybetmesine bağlı olarak petrol fiyatı da $\mathrm{Po}_{5}$ düzeyinden $\mathrm{P}_{15}$ düzeyine yükselecektir.

Ikinci yaklaşım ise ödemeler dengesi yaklaşımıdır (Krugman, 1983; Golup, 1983; Zhang, 2013; Basher vd., 2016). Bu yaklaşıma göre emtia fiyatlarındaki artış emtia ithal eden ülkelerden emtia ihraç eden ülkelere doğru bir servet transferine yol açmaktadır. Emtia ihraç eden ülkeler bu kapsamda elde ettikleri gelirleri kısa vadede ABD dolarına dayalı varlıklarda değerlendirmektedirler. $\mathrm{Bu}$ da kısa vadede $A B D$ dolarının değerlenmesine yol açabilmektedir. Uzun vadede ise emtia ihraç eden ülkelerin elde ettikleri servetler tüketime yönelmektedir. Bu tüketimin dünyanın çeşitli bölgelerine yönelmesi (Örneğin Euro bölgesi, Uzak doğu Asya gibi) ise ABD dolarının satılarak diğer ülke para birimlerinin talep edilmesine yol açtığından uzun vadede $A B D$ dolarının değer kaybetmesine yol açabilmektedir. Nitekim finansal 
piyasaların bu bilgiye sahip olması nedeniyle de bu etki çok daha hızlı bir şekilde ortaya çıkabilmektedir.

Literatürde ilgi gören bir diğer yaklaşım ise $A B D$ dolarındaki değişimlerin petrol fiyatı üzerinden diğer emtia fiyatları üzerinde etkili olabileceğini ifade eden yaklaşımıdır (Holtham, 1988; Gilbert, 1989; Borensztein ve Reinhart, 1994; Baffes, 2007; Nazlıoğlu ve Soytas, 2012; Coudert vd.,, 2013; Akram, 2009). Bu yaklaşıma göre yukarıda belirtilen yaklaşımlara bağlı olarak öncelikle ABD dolarının değerindeki değişimler petrol fiyatlarında değişime yol açabilmekte ardından ise değişen petrol fiyatları diğer emtia fiyatlarında da benzer etkilere yol açabilmektedir. Örneğin, talep yönünden yaklaşıldığında, doların küresel bazda değer kaybetmesi sonucunda petrol fiyatları artış gösterdiğinde, harcanabilir geliri artan petrol ihraç eden ülkeler kendi ekonomilerinin ihtiyaç duyduğu diğer emtialara olan taleplerini artırmakta bu da diğer emtiaların fiyatlarında artışa yol açabilmektedir. Ayrıca, ikame etkisine bağlı olarak petrol fiyatlarındaki artış, diğer ülkeleri doğalgaz ve kömür gibi alternatif enerji kaynaklarına yöneltebilmekte bu da petrol-dışı enerji emtiaları fiyatlarında artışa yol açabilmektedir. Dahası, artan petrol fiyatlarının yarattığı küresel enflasyonist baskı yatırımcıları güvenli liman arayışı ile başta altın olmak üzere çeşitli değerli metallere yöneltebilmekte bu da bu tip emtiaların da fiyatlarında artışa yol açabilmektedir. Arz yönlü olarak bakıldığında ise petrol, üretim süreçlerinde kullanılan bir girdi olduğundan petrol fiyatlarındaki artış diğer emtiaların üretim ve taşıma maliyetlerinde de artışa yol açabilmektedir. Bu da diğer emtiaların satış fiyatlarına yansıyabilmektedir.

$\mathrm{Bu}$ kapsamda literatüre bakıldığında $A B D$ dolarının çeşitli emtialar üzerindeki etkisinin incelendiğini ve bu çalışmalarda genel olarak $A B D$ dolarındaki hareketlerin kısa ve / veya uzun dönemde emtia fiyatları üzerinde etkili olduğunun ifade edildiği görülmektedir (Sari vd., 2010; Frank ve Garcia, 2010; Beckmann ve Czudaj, 2013; Zhang vd., 2008; Jin ve Fan, 2012; Bloomberg ve Harris, 1995).

$\mathrm{Bu}$ çalışmanın amacı emtia piyasalarındaki fiyat hareketlerinin açıklanmasında ABD doların küresel bazdaki değerinde meydana gelen değişimlerin etkisinin incelenmesidir. Çalışmanın literatüre katkısı şu şekilde ifade edilebilir: Öncelikle literatürdeki çalışmaların genelde sınırlı sayıda emtiayı inceledikleri görülmektedir. Bu çalışmada ise ABD dolarındaki fiyat hareketlerinin gıda, içecek, metal, yakıt, petrol ve tarımsal emtialar olmak üzere
6 farklı emtia grubu üzerindeki etkisi incelenmiştir. íkinci olarak da literatürde değişkenler arasındaki ilişki incelenirken yapısal kırılmaların pek dikkate alınmadığı görülmektedir. Halbuki, finansal krizler, teknolojik gelişmeler, iktisadi birimlerin davranışındaki değişimler yapısal değişimlere yol açabilmektedir. Bu kapsamda 2007-2008 küresel krizi, 2011 yılında yaşanan Arap baharı, yükselen piyasa ekonomilerinin emtia talebindeki değişimler, emtia piyasalarının giderek daha liberal hale gelmesi gibi gelişmeler çeşitli yapısal değişimlere yol açmış olabilir (Fan ve Xu, 2011). Bu nedenle bu çalışmada çoklu yapısal kırılmalara izin veren Maki (2012) koentegrasyon testinden yararlanılmıştır. Üçüncü olarak ise $A B D$ dolarının değer kazanması ile değer kaybının emtia fiyatları üzerindeki etkisinin farklı olması beklenmektedir. Fakat, literatürde nedensellik analizlerinde daha çok Granger nedensellik testi gibi standart nedensellik testlerinin kullanıldığı görülmektedir. Bu çalışmada ise Hatemi-J (2012) tarafından yeni geliştirilen asimetrik nedensellik testinden yararlanılmıştır. Böylece, ABD dolarının değer kazancı ile kaybının emtia fiyatları üzerindeki etkisi ayrı ayrı incelenebilmiştir.

\section{VERI ve METODOLOJi}

\subsection{Veri}

Çalışma Ocak 1999 ile Şubat 2015 dönemini kapsamakta ve aylık verilerden oluşmaktadır. Çalışmanın başlangıç yılının 1999 olarak seçilmesinin nedeni literatürde genel olarak özellikle enerji emtialardaki sert fiyat hareketlerinin 1999 yılı ile başladığının ifade edilmesidir. ABD dolarını temsilen geniş tanımlı reel efektif ABD dolar endeksi (Broad Dollarindex) kullanılmıştır. Emtia olarak IMF tarafından yayınlanan gıda, içecek, metal, yakıt, petrol ve tarımsal emtia fiyat endekslerinden yararlanılmıştır. Gıda emtia endeksi tahıl, şeker, meyve, et, deniz ürünleri ve bitkisel yağdan; içeceğe dayalı emtia endeksi kahve, çay ve kakaolu içeceklerden; metal emtia endeksi alüminyum, demir cevheri, nikel, çinko, kurşun, kalay ve uranyumdan; yakıt emtia endeksi doğalgaz, ham petrol ve kömürden; petrol emtia endeksi WTI, Brent ve Dubai petrollerinin ortalama fiyatından; tarımsal emtia endeksi ise kereste, pamuk, kauçuk ve deriden oluşmaktadır'. Çalışma boyunca gıda, içecek, metal, yakıt, petrol ve tarımsal emtialar için sırasıyla rfd, rbvr, rmtl, rfuel, roil ve ragrc; reel efektif döviz kuru içinse rbrd ifadeleri kullanılmıştır. ABD dolarına ilişkin veriler $A B D$ merkez bankasından, emtialara ilişkin veriler ise 
IMF'den temin edilmiştir. Emtia fiyatları ABD tüketici endeksi (CPI) kullanılarak reel hale getirilmiştir. ABD CPI verisi Eurostat'tan temin edilmiştir. Çalışmada değişkenlerin logaritmik değerleri kullanılmıştır.

\subsection{Metodoloji}

Çalışmada değişkenler arasındaki uzun dönemli ilişki analizinde öncelikle Johansen (1988) koentegrasyon testinden yararlanılmıştır. Johansen (1988) koentegrasyon testinin amacı katsayılar matrisinin (П) değişkenler arasındaki uzun dönemli ilişki hakkında bilgi içerip içermediğinin araştırımasıdır. Bu amaçla çalışmada diğerlerinin yanı sıra Zhang vd.'nın (2008) çalışmalarında olduğu gibi Denklem (1)'deki model dikkate alınmıştır:

$$
\text { lncomdty }_{t}=c_{0}+\beta_{1} \operatorname{lnrbrd}_{t}+\xi_{t}
$$

Burada, lncomdty $y_{t}$ çalışmada kullanılan reel logaritmik emtia endekslerini, $\operatorname{lnrbrd}_{t}$ ABD dolarının değerini temsilen kullanılan reel efektif döviz kurunu, $c_{0}$ sabit terimi, $\xi_{t}$ hata terimini, $\beta$ ise eğim parametresini ifade etmektedir.

Fakat, Johansen (1988) koentegrasyon testinin bir eksikliği olası yapısal kırılmaları dikkate almamasıdır. Literatürde yaygın bir şekilde ifade edildiği gibi bu durum değişkenler arasında koentegre ilişki olmadığı gibi yanlı bir sonuç elde edilmesine yol açabilmektedir. Bu nedenle çalışmada Bai ve Perron $(1998,2003)$ çoklu yapısal kırılma testinden yararlanılarak modelin yapısal kırılmalar içerip içermediği de incelenmiştir. Bai ve Perron $(1998,2003)$ testi $U D \max , \mathrm{WD} \max , S u b F_{T}$ ve $S E Q F_{T}$ o I m a k üzere dört test istatistiği ile $B I C$ ve $L W Z$ olmak üzere iki adet bilgi kriterinden oluşmaktadır. Yapısal kırımalar altında serilerin durağanlık özelliklerinin incelenmesinde ise Carrion-i Silvestre vd. (2009) çoklu yapısal kırılmalı birim kök testinden yararlanılmıştır. $\mathrm{Bu}$ test serilerin sabit terim ve trendinde beş yapısal kırılmaya izin verebilen bir testtir. Bu test quasi-GLS yani genelleştirilmiş en küçük kareler (generalized least squares) yöntemine dayanmakta ve $P_{T}^{G L S}, \mathrm{MP}_{T}^{G L S} M Z_{\alpha}^{G L S}, M S B^{G L S}$ ve $M Z_{T}^{G L S}$ olmaküzere beş adet test istatistiğinden oluşmaktadır. Bu test istatistiklerinin tamamının Ho hipotezi "birim kök vardır" şeklindedir. Hesaplanan test istatistikleri kritik tablo değerinden küçük ise Ho hipotezi reddedilmektedir. Aksi takdirde, serilerde birim kök olduğu sonucuna ulaşılmaktadır. Çalışmada yapısal kırılmalar altında değişkenler arasında uzun dönemli bir ilişki olup olmadığının analizinde ise Maki (2012) çoklu yapısal kırılmalı koentegrasyon testinden yararlanılmıştır. Bu test Engle-Granger (1987) testi gibi hata düzeltme terimine dayalı (residual-based) bir testtir. Testin Ho hipotezi "yapısal kırılma yoktur" şeklindedir. Bu test modelde beş yapısal kırılmaya ve / veya rejim değişimine izin verebilmektedir². Bu kapsamda Denklem (1)'deki model rejim değişimine izin verecek şekilde Denklem (2)'deki gibi gösterilebilir.

$$
\ln \operatorname{comdty}_{t}=c_{0}+\sum_{i=1}^{k} c_{i} D_{i t}+\beta_{i} \ln r b r d_{t}+\sum_{i=1}^{k} \beta_{i} D_{i t}+\beta_{i} \ln r b r d_{t}+\varepsilon_{t}
$$

Burada $k$ maksimum yapısal kırılma sayısını; $D_{i t}$ ise aşağıda tanımlandığı gibi kukla değişkenleri temsil etmektedir:

$$
D_{i t}=\left\{\begin{array}{l}
0 \text { if } t \leq T_{B i}, i=1,2, \ldots .5 \\
1 \text { if } t \succ T_{B i}, i=1,2, \ldots .5
\end{array}\right\}
$$

$T_{B i}$ ise yapısal kırılma dönemini göstermektedir.

Nedensellik analizinde ise Hatemi-J (2012) tarafından geliştirilen asimetrik nedensellik testinden

$$
y_{1 t}^{+}=\sum_{i=1}^{t} \varepsilon_{1 i}^{+}, y_{1 t}^{-}=\sum_{i=1}^{t} \varepsilon_{1 i}^{-}, y_{2 t}^{+}=\sum_{i=1}^{t} \varepsilon_{2 i}^{+} y_{2 t}^{-}=\sum_{i=1}^{t} \varepsilon_{2 i}^{-},
$$

Bundan sonraki aşama ise belirtilen bu kümülatif negatif ve kümülatif pozitif değişkenler arasındaki nedensellik ilişkisinin incelenmesidir. Bu amaçla da nedensellik analizinde kullanılacak gecikme uzunluğunun belirlenmesi gerekmektedir. Çalışmada bu yararlanılmıştır. Bu test kümülatif negatif ve kümülatif pozitif şokları birbirinden ayrıştırarak herhangi bir değişkendeki negatif bir değişimin bir diğer ifadeyle azalışın diğer bir değişkende de bir azalışa yol açıp açmadığı ve / veya herhangi bir değişkendeki bir artışın diğer bir değişkende de artışa yol açıp açmadığını sınayabilmektedir. Bu kapsamda $y_{1 t}$ ve $y_{2 t}$ iki bütünleşik seri olacak şekilde bu değişkenler için kümülatif pozitif ve kümülatif negatif şoklar Denklem (3)'te gösterildiği gibi ifade edilebilir:

amaçla Hatemi-J (2012) tarafından tavsiye edilen ve yeni bir bilgi kriteri olan HJC kriterinden yararlanılmıştır. 


\section{BULGULAR}

Değişkenlerin durağanlık özeliklerinin tespiti amaciyla Philips ve Perron (PP) birim kök testinden yararlanılmıştır. Trendli ve trendsiz model formları dikkate alınarak uygulanan birim kök testi sonuçları \%5 anlamlılık düzeyinde serilerin serilerin birinci dereceden bütünleşik yani I(1) olduklarına işaret etmektedir ${ }^{3}$. Johansen (1988) koentegrasyon testi sonuçları Tablo 1'de sunulmuştur. Sonuçlar incelendiğinde $A B D$ reel efektif döviz kuru ileyakıt, ham petrol ve gıda emtiaları arasında uzun dönemli bir ilişki olduğu, metal, içecek ve tarımsal emtialar arasında ise uzun dönemli bir ilişki bulunmadığı anlaşımaktadır. Uzun dönem parametre tahminine gelince, en çok olabilirlik (MLE) yöntemi sonuçlarına göre reel efektif döviz kurundaki artışlar uzun dönemde ham petrol, yakıt ve gıda emtialarının fiyatlarında düşüşe yol açmaktadır. Daha somut bir şekilde ifade etmek gerekirse uzun dönemde ABD dolarının \%1 değer kazanmasının yakıt ve ham petrolde sırasıyla yaklaşık $\% 0.94$ ve \% 0.95 'lik bir azalışa yol açtığı gıda fiyatları üzerindeki etkisinin ise \%0.44'lük bir azalış ile göreceli olarak daha sınırlı kaldığı anlaşılmaktadır. Daha önce değinildiği gibi 1999-2015 döneminde yaşanan bazı gelişmeler reel döviz kuru ile emtia fiyatları arasındaki ilişkide yapısal değişimlere yol açmış olabilir. Ayrıca, reel efektif döviz kuru ile metal, tarımsal emtia ve içeceğe dayalı emtialar arasında uzun dönemli bir ilişkinin bulunamamasının bir nedeni de olası yapısal kırımaların dikkate alınmamış olması olabilir. Bu nedenle öncelikle ilgili tüm değişkenlerin yapısal bir değişim içerip içermediği Bai ve Perron $(1999,2003)$ yapısal kırılma testi ile incelenmiştir.

Tablo 1: Johansen (1998) Koentegrasyon Testi Sonuçları

\begin{tabular}{|c|c|c|c|c|c|c|}
\hline & Ho & Trace & Maksimum & $\Delta$ & ECT & B-MLE \\
\hline rfd-rbrd & $\begin{array}{l}r=0 \\
r \leq 1\end{array}$ & $\begin{array}{l}22.999 * *[15.494] \\
1.8212[3.841]\end{array}$ & $\begin{array}{l}21.178^{* *}[14.264] \\
1.8212[3.841]\end{array}$ & 2 & $-0.107^{* *}[-3.247]$ & $\begin{array}{l}-0.441^{* *} \\
{[15.401]}\end{array}$ \\
\hline rbvr-rbrd & $\begin{array}{l}r=0 \\
r \leq 1\end{array}$ & $\begin{array}{l}8.936[15.494] \\
1.664[3.841]\end{array}$ & $\begin{array}{l}7.272[14.264] \\
1.664[3.841]\end{array}$ & 4 & - & \\
\hline ragrc-rbrd & $\begin{array}{l}r=0 \\
r \leq 1\end{array}$ & $\begin{array}{l}12.063[15.494] \\
1.272[3.841]\end{array}$ & $\begin{array}{l}10.791[14.264] \\
1.272[3.841]\end{array}$ & 3 & - & \\
\hline rmtl-rbrd & $\begin{array}{l}r=0 \\
r \leq 1\end{array}$ & $\begin{array}{l}12.456[15.494] \\
3.241[3.841]\end{array}$ & $\begin{array}{l}9.215[14.264] \\
3.241[3.841]\end{array}$ & 2 & - & \\
\hline rfuel-rbrd & $\begin{array}{l}r=0 \\
r \leq 1\end{array}$ & $\begin{array}{l}30.814^{* *}[15.494] \\
2.128[3.841]\end{array}$ & $\begin{array}{l}28.685^{* *}[14.264] \\
2.1284[3.841]\end{array}$ & 2 & $-0.104 *[-4.922]$ & $\begin{array}{l}-0.937^{* *} \\
{[10.534]}\end{array}$ \\
\hline roil-rbrd & $\begin{array}{l}r=0 \\
r \leq 1\end{array}$ & $\begin{array}{l}25.002 * *[15.494] \\
1.525[3.841]\end{array}$ & $\begin{array}{l}23.476^{* *}[14.264] \\
1.525[3.841]\end{array}$ & 3 & $-0.113^{* *}[-4.416]$ & $\begin{array}{l}-0.949^{* *} \\
{[9.720]}\end{array}$ \\
\hline
\end{tabular}

** \%5 anlamlılık düzeyini göstermektedir. Kritik tablo değerleri köșeli parantez içerisinde gösterilmiștir. Uygun gecikme uzunluğu maksimum gecikme 12 olacak şekilde AIC kriteri dikkate alınarak Vektör otoregresif model (VAR) ile belirlenmiştir. Bulunan gecikme otokorelasyon sorununu gideremediğinde gecikme birer birer artııılmışıı. $\Delta$, serilerin düzey değerleri dikkate alınarak belirlenen optimal gecikme uzunluğunu göstermektedir. Johansen (1988) testi uygulanırken bu gecikme uzunlukları bir azaltılmıştır. Belirlenen gecikmelerin istikrarlıık koşulunu da sağladığı görülmüştür. ECT hata düzeltme terimini, B-MLE ise en çok olabilirlik yöntemine dayalı olarak tahmin edilen uzun dönem parametrelerini ifade etmektedir.

Bu kapsamda serilere ait grafikler serilerin hem sabit terim hem de trendinde değişimler olabileceğine işaret ettiğinden Bai ve Perron $(1998,2003)$ testi uygulanırken de serilerin sabit terim ve trendinde bir değişim olup olmadığı sınanmıştır . Bu kapsamda elde edilen sonuçlar Tablo 2'de sunulmuştur. Sonuçlar incelendiğinde UDmax ve WDmax test istatistiklerinin \%5 anlamlılık düzeyinde tarımsal emtialar dışındaki tüm değişkelerin sabit terim ve trendinde yapısal değişimler olduğuna işaret ettiği görülmektedir. Yapısal kırılma sayılarının tespitine gelince $S u b F_{T}$ ve $S E Q F_{T}$ test istatistikleri ile BIC ve LWZ kriterlerinin birbirinden farklı yapısal kırılmalara işaret ettiği görülmektedir. Bai ve Perron $(1998,2003)$ bu tür durumlarda yapısal kırılma sayıların $S E Q F_{T}$ test istatistiğine göre 
Tablo 2: Bai ve Perron $(1998,2003)$ Yapısal Kırılma Testi Sonuçları

\begin{tabular}{|c|c|c|c|c|c|}
\hline & \multicolumn{2}{|l|}{ UDmax } & \multicolumn{2}{|l|}{ WDmax } & \\
\hline Rfd & \multicolumn{2}{|l|}{$24.8848^{*}$} & \multicolumn{2}{|l|}{$54.6065^{*}$} & \\
\hline Rbvr & \multicolumn{2}{|l|}{$13.9442 *$} & \multicolumn{2}{|l|}{$18.3836^{*}$} & \\
\hline Ragrc & \multicolumn{2}{|l|}{3.1633} & \multicolumn{2}{|l|}{6.9416} & \\
\hline Rmtl & \multicolumn{2}{|l|}{ 27.1001* } & \multicolumn{2}{|l|}{$57.6438^{*}$} & \\
\hline Rfuel & \multicolumn{2}{|l|}{$21.8200^{*}$} & \multicolumn{2}{|l|}{$47.8813^{*}$} & \\
\hline Roil & \multicolumn{2}{|l|}{$25.0198^{*}$} & \multicolumn{2}{|l|}{$49.3736^{*}$} & \\
\hline Rbrd & \multicolumn{2}{|l|}{$9.5842^{*}$} & \multicolumn{2}{|l|}{$18.2706^{*}$} & \\
\hline $\mathrm{SubF}_{T}$ & \multicolumn{2}{|l|}{ SubF(0|1) } & SubF(0 $\mid 3)$ & SubF(0|4) & SubF(0 $\mid 5)$ \\
\hline Rfd & 7.5034 & $12.6151^{*}$ & $10.7336^{*}$ & $7.6513^{*}$ & $24.8848^{*}$ \\
\hline Rbvr & $13.9442^{*}$ & $11.1224^{*}$ & $10.7262^{*}$ & 9.8993* & $8.3776^{*}$ \\
\hline Rmtl & 0.20010 & 9.7023* & $10.9626^{*}$ & $27.1001^{*}$ & $26.2689^{*}$ \\
\hline Rfuel & 19.4279* & $19.3898^{*}$ & $14.3836^{*}$ & $21.5506^{*}$ & $21.8200^{*}$ \\
\hline Roil & $20.0722^{*}$ & $25.0198^{*}$ & 9.9989* & $20.9272^{*}$ & $22.5001^{*}$ \\
\hline Rbrd & 1.2932 & $7.3394^{*}$ & $9.5842^{*}$ & 3.6406 & $8.3261^{*}$ \\
\hline$S E Q F_{T}$ & SubF(1 | 2) & $\operatorname{SubF}(2 \mid 3)$ & $\operatorname{SubF}(3 \mid 4)$ & SubF(4|5) & $\mathrm{k}$ \\
\hline Rfd & 7.0733 & 0.4213 & 0.0000 & 0.0000 & 1 \\
\hline Rbvr & 5.3419 & 0.7871 & 0.2957 & 0.2957 & 1 \\
\hline Rmtl & 4.5492 & 1.2168 & 1.2168 & 1.2168 & 1 \\
\hline Rfuel & 1.6897 & 0.8731 & 0.2067 & 0.0000 & 1 \\
\hline Roil & 2.3546 & 2.5313 & 0.1549 & 0.0000 & 1 \\
\hline Rbrd & 6.4218 & 1.0038 & 0.0000 & 0.0000 & 1 \\
\hline $\mathrm{BIC}$ & $m=1$ & $m=2$ & $m=3$ & $m=4$ & $m=5$ \\
\hline Rfd & -7.7741 & -8.1116 & $\underline{-8.3494}$ & -8.2938 & -8.1895 \\
\hline Rbvr & -6.9743 & -7.1516 & -7.2003 & -7.3020 & -7.2967 \\
\hline Rmtl & -6.4136 & -6.7424 & -6.7859 & $\underline{-6.9310}$ & -6.9292 \\
\hline Rfuel & -5.9208 & -6.1319 & -6.1587 & $\underline{-6.1773}$ & -6.1051 \\
\hline Roil & -5.7827 & -5.9509 & $\underline{-6.0037}$ & -6.0035 & -5.9318 \\
\hline Rbrd & -6.0125 & -6.4611 & -6.6667 & $\underline{-6.7731}$ & -6.6971 \\
\hline LWZ & $m=1$ & $m=2$ & $m=3$ & $m=4$ & $m=5$ \\
\hline Rfd & -7.6885 & $\underline{-7.9687}$ & $\underline{-8.1493}$ & -8.0362 & -7.8743 \\
\hline Rbvr & -6.8887 & -7.0087 & -7.0001 & -7.0444 & -6.9815 \\
\hline Rmtl & -6.3279 & -6.5995 & -6.5857 & $\underline{-6.6734}$ & -6.6140 \\
\hline Rfuel & -5.8352 & $\underline{-5.9891}$ & -5.9586 & -5.9197 & -5.7898 \\
\hline Roil & -5.6972 & -5.8082 & $\underline{-5.8035}$ & -5.7458 & -5.6165 \\
\hline Rbrd & -5.9268 & -6.3183 & -6.4665 & -6.5155 & -6.3819 \\
\hline
\end{tabular}

*, \%5 anlamlılık düzeyini göstermektedir. Triminaj 0.15, maksimum yapısal kırılma sayısı ise 5 alınmıştır. UDmax ve WDmax test istatistiklerinin \%5 anlamlılık düzeyindeki kritik tablo değerleri sırasıyla 8.88 ve 9.91 'dir. Hata teriminin dağılımının yapısal kırılmalar arasında değișmesine izin verilmisttir. m, LWZ ve BIC için yapısal kııılma sayılarını, altı çizili değerler ise bu kriterlerce belirlenen kırılma sayılarını ifade etmektedir. k ise $S E Q F_{T}$ tarafından belirlenen yapısal kırılma sayısını göstermektedir. 
belirlenmesini tavsiye etmiştir. Bulgular bu kapsamda değerlendirildiğinde $S E Q F_{T}$ test istatistiğinin ilgili değişkenlerin tamamı için tek bir yapısal kırılmanın geçerli olduğuna işaret ettiği görülmektedir. Bu durumda da öncelikle ilgili değişkenlerin yapısal kırılmalar altında da I(1) olup olmadığının incelenmesi gerekmektedir. İlgili değişkenler için $S E Q F_{T}$ tarafından belirlenen yapısal kırılma sayıları dikkate alınarak uygulanan Carrion-i Silvestre vd. (2009) yapısal kırılmalı birim kök testi sonuçları Tablo 3'te sunulmuştur.

Tablo 3: Carrion-i Silvestre vd. (2009) Çoklu Yapısal Kırılmalı Birim Kök Testi Sonuçları

\begin{tabular}{|l|l|l|l|l|l|l|}
\hline & PT & MPT & MZA & MSB & MZT & Kırılma tarihleri \\
\hline Rfd & 18.3711 & 18.4906 & -7.8749 & 0.2187 & -1.7222 & 07.2000 \\
& $\underline{6.9891}$ & $\underline{6.9891}$ & $\underline{-21.6724}$ & $\underline{0.1475}$ & $\underline{-3.2868}$ & \\
\hline Rbvr & 19.3235 & 18.8252 & -7.7741 & 0.2452 & -1.9059 & 10.2001 \\
& $\underline{6.5683}$ & $\underline{6.5683}$ & $\underline{-22.9072}$ & $\underline{0.1460}$ & $\underline{-3.3625}$ & \\
\hline Rmtl & 27.4752 & 26.8083 & -5.4676 & 0.3018 & -1.6499 & 02.2011 \\
& $\underline{6.8533}$ & $\underline{6.8533}$ & $\underline{-21.8472}$ & $\underline{0.1484}$ & $\underline{-3.3008}$ & \\
\hline Rfuel & 19.4768 & 18.0843 & -8.1138 & 0.2347 & -1.9042 & 07.2008 \\
& $\underline{6.4488}$ & $\underline{6.4488}$ & $\underline{-23.1456}$ & $\underline{0.1466}$ & $\underline{-3.3839}$ & \\
\hline Roil & 17.2775 & 16.0522 & -9.1815 & 0.2220 & -2.0385 & 07.2008 \\
& $\underline{6.3967}$ & $\underline{6.3967}$ & $\underline{-23.1368}$ & $\underline{0.1468}$ & $\underline{-3.3824}$ & \\
\hline Rbrd & 30.6843 & 30.2372 & -3.1194 & 0.2596 & -0.8098 & 02.2002 \\
& $\underline{6.4944}$ & $\underline{6.4944}$ & $\underline{-23.1187}$ & $\underline{0.1458}$ & $\underline{-3.3755}$ & \\
\hline
\end{tabular}

*, \%5 anlamlılık düzeyini ifade etmektedir. Optimal gecikme uzunluğu MAIC ile belirlenmiştir. \%5 anlamlılık düzeyindeki kritik değerler italik ve altı çizili olarak gösterilmiştir.

Sonuçlar incelendiğinde PT, MPT, MZA, MSB ve MZT test istatistiklerinin tamamının değişkenlerin düzey değerlerinde durağan olmadığına işaret ettiği görülmektedir. Maki (2012) koentegrasyon testine gelince, bu test daha önce belirtildiği gibi bir modelde 5 yapısal kırılmaya izin verebilmektedir. Fakat, Maki'nin (2012) ifade ettiği gibi modelde kullanılacak yapısal kırılma sayısının doğru belirlenmemesi analizlerde yanlış model spesifikasyonlarının kullanıımasına yol açabilmektedir. Bu nedenle öncelikle çalışmada kullanılacak 6 farklı modelin tamamında bir rejim değişimi olup olmadığı ve eğer bir rejim değişimi var ise sayısının ne olduğunun belirlenmesi amacıyla Denklem (1)'deki model dikkate alınarak yine Bai ve Perron $(1999,2003)$ testinden yararlanılmıştır - Bu kapsamda elde edilen sonuçlar Tablo 4'te sunulmuştur. Sonuçlar incelendiğinde UDmax ve WDmax test istatistiklerinin $\% 5$ anlamlılık düzeyinde 6 farklı model spesifikasyonunun tamamında en az bir kez rejim değişiminin olduğuna işaret ettiği görülmektedir. Rejim değişim sayılarının tespiti amaciyla kullanılan $S u b F_{T}$ ve $S E Q F_{T}$ test istatistikleri ile BIC ve LWZ kriterlerinden elde edilen sonuçlara bakıldığında ise yine bu testlerin birbirinden farklı rejim değişim sayılarına işaret ettiği görülmektedir. Bu kapsamda yine $S E Q F_{T}$ test istatistiği dikkate alındığında rfd-rbrd, rfuel-rbrd ile roil-rbrd model spesifikasyonlarında 2; rbvr-rbrd, ragr-rbrd ile rmtl-rbrd model spesifikasyonlarında ise 3 farklı rejim döneminin söz konusu olduğu ifade edilebilir. Her bir model için bu durum dikkate alınarak uygulanan Maki (2012) koentegrasyon testi sonuçları Tablo 5'te sunulmuştur ${ }^{5}$. Sonuçlar incelendiğinde, rallrbrd ile ruel-rbrd arasında \%10 anlamlılık düzeyinde; rfd-rbrd ve roil-rbrd arasında ise $\% 5$ anlamlılık düzeyinde koentegre ilişki olmadığını ifade eden Ho hipotezinin reddedildiği görülmektedir. Dolayısıyla, reel efektif döviz kuru ile gıda, ham petrol ve yakıt emtiaları arasında uzun dönemli bir ilişki olduğu anlaşılmaktadır. Reel efektif döviz kuru ile içecek, tarım ve metal emtiaları arasında ise yine herhangi bir uzun dönemli ilişkiye rastlanmamıştır. Dolayısıyla, Maki (2012) koentegrasyon testinin de Johansen (1988) koentegrasyon testi ile benzer sonuçlara işaret ettiği anlaşılmaktadır. 
Tablo 4: Bai ve Perron $(1998,2003)$ Yapısal Kırılma Testi Sonuçları

\begin{tabular}{|c|c|c|c|c|c|}
\hline & \multicolumn{2}{|l|}{ UDmax } & \multicolumn{2}{|l|}{ WDmax } & \\
\hline rfd-rbrd & \multicolumn{2}{|l|}{$25.7024^{*}$} & \multicolumn{2}{|l|}{$41.1362^{*}$} & \\
\hline rbvr-rbrd & \multicolumn{2}{|l|}{$28.9859^{*}$} & \multicolumn{2}{|l|}{$48.5336^{*}$} & \\
\hline ragr-rbrd & \multicolumn{2}{|l|}{$36.3223^{*}$} & \multicolumn{2}{|l|}{$71.2166^{*}$} & \\
\hline rmtl-rbrd & \multicolumn{2}{|l|}{$60.8304^{*}$} & \multicolumn{2}{|l|}{ 119.269* } & \\
\hline rfuel-rbrd & \multicolumn{2}{|l|}{$14.2083^{*}$} & \multicolumn{2}{|l|}{$21.5866^{*}$} & \\
\hline roil-rbrd & \multicolumn{2}{|l|}{$15.1484^{*}$} & \multicolumn{2}{|l|}{$27.6474^{*}$} & \\
\hline$S u b F_{T}$ & SubF(0 | 1) & SubF(0 | 2) & $\operatorname{SubF}(0 \mid 3)$ & SubF(0|4) & SubF(0 I 5) \\
\hline rfd-rbrd & 7.7046 & $25.7024^{*}$ & $21.5684^{*}$ & $17.4633^{*}$ & $20.9805^{*}$ \\
\hline rbvr-rbrd & 4.9196 & $20.7892^{*}$ & 8.3404 & 28.9859* & $24.7534^{*}$ \\
\hline ragr-rbrd & 5.3606 & $16.8788^{*}$ & $18.8275^{*}$ & $28.4417^{*}$ & $36.3224^{*}$ \\
\hline rmtl-rbrd & 2.7184 & 29.7096* & $8.9243^{*}$ & $32.7867^{*}$ & $60.8304^{*}$ \\
\hline rfuel-rbrd & 14.2083* & 9.2925 & $12.3323^{*}$ & $12.9866^{*}$ & $11.0097^{*}$ \\
\hline roil-rbrd & $15.1484^{*}$ & 8.8382 & $13.7500^{*}$ & $13.2806^{*}$ & $14.1008^{*}$ \\
\hline$S E Q F_{T}$ & SubF(1 | 2) & $\operatorname{SubF}(2 \mid 3)$ & $\operatorname{SubF(3|4)}$ & SubF(4 I 5) & K \\
\hline rfd-rbrd & 4.9205 & 4.365 & 0.6964 & 0.6964 & 1 \\
\hline rbvr-rbrd & $20.2529^{*}$ & 6.5915 & $37.7174^{*}$ & 0.0000 & 2 \\
\hline ragr-rbrd & $29.5322^{*}$ & 6.5841 & 0.1560 & 0.0000 & 2 \\
\hline rmtl-rbrd & $16.2495^{*}$ & 8.4145 & 9.9027 & 0.0000 & 2 \\
\hline rfuel-rbrd & 4.1785 & $16.6546^{*}$ & 14.2714 & 0.0000 & 1 \\
\hline roil-rbrd & 3.2227 & $18.5832^{*}$ & 9.2754 & 0.0000 & 1 \\
\hline $\mathrm{BIC}$ & $m=1$ & $m=2$ & $m=3$ & $m=4$ & $m=5$ \\
\hline rfd-rbrd & -8.9921 & -9.1614 & -9.1940 & $\underline{-9.1948}$ & -9.1328 \\
\hline rbvr-rbrd & -7.5279 & -7.7403 & -7.9330 & $\underline{-8.2248}$ & -8.0426 \\
\hline ragr-rbrd & -8.5198 & -8.7971 & -9.0206 & -8.9931 & -8.9285 \\
\hline rmtl-rbrd & -6.8617 & -7.1513 & -7.3518 & -7.6478 & -7.6343 \\
\hline rfuel-rbrd & -6.6508 & -6.8197 & -7.0211 & -6.9952 & -6.8252 \\
\hline roil-rbrd & -6.4634 & -6.5826 & $\underline{-6.7978}$ & -6.7671 & -6.6309 \\
\hline LWZ & $m=1$ & $m=2$ & $m=3$ & $\mathrm{~m}=4$ & $m=5$ \\
\hline rfd-rbrd & -8.8493 & $\underline{-8.9326}$ & -8.8788 & -8.7930 & -8.6441 \\
\hline rbvr-rbrd & -7.3851 & -7.5114 & -7.6178 & $\underline{-7.8223}$ & -7.5540 \\
\hline ragr-rbrd & -8.3770 & -8.5681 & $\underline{-8.7054}$ & -8.5913 & -8.4399 \\
\hline rmtl-rbrd & -6.7188 & -6.9223 & -7.0366 & $\underline{-7.2460}$ & -7.1456 \\
\hline rfuel-rbrd & -6.5079 & -6.5908 & $\underline{-6.7059}$ & -6.59335 & -6.3366 \\
\hline roil-rbrd & -6.3206 & -6.3537 & $\underline{-6.4827}$ & -6.3653 & -6.1423 \\
\hline
\end{tabular}

*, \%5 anlamlılık düzeyini göstermektedir. Triminaj 0.15, maksimum yapısal kırılma sayısı ise 5 alınmıştır. UDmax ve WDmax test istatistiklerinin \%5 anlamlılık düzeyindeki kritik tablo değerleri sırasıyla 11.70 ve 12.81 'dir . Hata teriminin dağılımının yapısal kırılmalar arasında değişmesine izin verilmiștir. $m$, LWZ ve BIC için yapısal kırılma sayılarını, altı çizili değerler ise bu kriterlerce belirlenen kırılma sayılarını ifade etmektedir. k ise $S E Q F_{T}$ tarafından belirlenen yapısal kırılma sayısını göstermektedir. 
Tablo 5: Maki (2012) Çoklu Yapısal Kırılmalı Koentegrasyon Testi Sonuçları

\begin{tabular}{|c|c|c|c|c|c|}
\hline \multirow{2}{*}{ 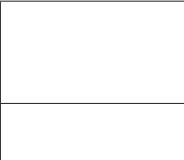 } & \multirow{2}{*}{ Maki test ist. } & \multirow{2}{*}{$\begin{array}{l}\text { Kritik tablo değerleri } \\
\% 1 \quad \% 5 \quad \% 10\end{array}$} & \multicolumn{3}{|c|}{ Rejim değişim tarihleri } \\
\hline & & & $\mathrm{T}_{\mathrm{B} 1}$ & & \\
\hline rfd-rbrd & $-5.9569 *$ & $-5.457-4.895-4.626$ & 11.2007 & - & - \\
\hline rbvr-rbrd & -4.9463 & $-5.863-5.363-5.070$ & 01.2008 & 09.2010 & - \\
\hline ragr-rbrd & -4.4697 & $-5.863-5.363-5.070$ & 07.2001 & 03.2010 & \\
\hline rmtl-rbrd & -3.9946 & $-5.863-5.363 \quad-5.070$ & 09.2002 & 11.2008 & - \\
\hline rfuel-rbrd & $-5.3841^{* *}$ & $-5.457-4.895-4.626$ & 09.2001 & - & - \\
\hline roil-rbrd & $-5.6772 *$ & $-5.457-4.895-4.626$ & 09.2001 & - & - \\
\hline
\end{tabular}

*,****** sırasıyla \%1, \%5 ve \%10 anlamlılık düzeyini göstermektedir. Triminaj 0.15 alınmıştır.

Aralarında uzun dönemli ilişki bulunan değişkenler için rejim değişimleri dikkate alınarak elde edilen uzun dönem parametre tahmin sonuçları Tablo 6'da sunulmuştur. Karşılaştırma imkanı sunması amacıyla da rejim değişimleri dikkate alınmadan tahmin edilen uzun dönem katsayılarına da Tablo 6'da yer verilmiştir. Öncelikle, rejim değişimleri dikkate alınmadan elde edilen uzun dönem parametrelerine bakıldığında her durumda reel efektif döviz kuru katsayısının negatif ve istatistiki olarak anlamlı olduğu ve 19992015 dönemi için ABD dolarındaki \%1'lik bir değer kazancının gıda, ham petrol ve yakıt emtialarının fiyatlarında sırasıyla yaklaşık $\% 0.44, \% 1.3$ ve $\% 1$ 'lik bir azalışa yol açtığı anlaşılmaktadır. Rejim değişim tarihleri dikkate alındığında ise Ocak 1999 ile Eylül 2001 tarihine kadar reel efektif döviz kuru ile ham petrol ve yakıt emtiaları arasında pozitif ve istatistiki olarak anlamlı bir ilişkinin bulunduğu, Eylül 2001 tarihinden sonra ise değişkenler arasındaki ilişkinin negatife döndüğü görülmektedir. Ayrıca, gerek rejim değişim tarihlerinin dikkate alındığı gerekse alınmadığı durumlarda düzeltilmiş $R^{2}$ değerlerinin oldukça yüksek olduğu görülmektedir.Bu da ilgili emtiaların fiyatlarında meydana gelen değişimin açıklanmasında $A B D$ reel efektif döviz kurunun önemli bir etkisi olduğu anlamına gelmektedir.

Tablo 6 : Uzun Dönem Parametre Tahmin Sonuçları

\begin{tabular}{|c|c|c|c|c|}
\hline & $c_{0}$ & $c_{1}$ & $\beta_{1}$ & $\beta_{2}$ \\
\hline \multicolumn{5}{|c|}{ Rejim değişimi dikkate alındığında } \\
\hline rfd-rbrd & $2.3785^{*}$ & $0.6827^{*}$ & $-0.2996^{*}$ & $-0.1468^{*}$ \\
\hline rfuel-rbrd & $-2.9140^{*}$ & $8.1515^{*}$ & $0.8094^{*}$ & $-1.7415^{*}$ \\
\hline roil-rbrd & $-2.7164^{*}$ & $8.1125^{*}$ & $0.7654^{*}$ & $-1.7327^{*}$ \\
\hline \multicolumn{5}{|c|}{ Rejim değişimi dikkate alınmadığında } \\
\hline & $\mathrm{C}_{0}$ & $\beta_{1}$ & $\operatorname{Adj}-R_{1}^{2}$ & Adj- $R_{2}^{2}$ \\
\hline rfd-rbrd & $3.0040^{*}$ & $-0.4346^{*}$ & 0.9082 & 0.9325 \\
\hline rfuel-rbrd & $5.5008^{*}$ & $-0.9922^{*}$ & 0.7841 & 0.8962 \\
\hline roil-rbrd & $5.6768^{*}$ & $-1.0313^{*}$ & 0.7803 & 0.8850 \\
\hline
\end{tabular}

*, \%5 anlamlılık düzeyini göstermektedir. Adj- $R^{2}$, rejim değişimi dikkate alınmadığında elde edilen düzeltilmiş $R^{2}$ değerini; Adj- $R^{2}$ ise rejim değişimi dikkate alındığında elde edilen düzeltilmiş $R^{2}$ değerini göstermektedir.

\subsection{Asimetrik Nedensellik Testi Sonuçları}

Çalışmanın bu kısmında değişkenler arasındaki asimetrik nedensellik ilişkisi analiz edilmiştir. Bu kapsamda şu iki sorunun yanıtı aranmıştır: (i) $A B D$ dolarındaki değer kayıpları emtia fiyatlarında artışa yol açmakta mıdır?. (ii) ABD dolarındaki değer kazançları emtia fiyatlarında düşüşe yol açmakta mıdır?. Bu amaçla da Hatemi-J (2012) asimetrik 
nedensellik testinden yararlanılmıştır. Bu test değişkenler arasında hem koentegre ilişki olduğu hem de olmadığı durumlarda kullanılabilmektedir. $\mathrm{Bu}$ test için öncelikle değişkenlerin durağanlık özelliklerinin ve maksimum entegrasyon derecesinin incelenmesi gerekmektedir. Çalışmada daha önce değişkenlere PP birim kök testi ile Carrion-i Silvestre vd. (2009) birim kök testi uygulanmış ve serilerin I(1), yani maksimum entegrasyon derecesinin de 1 olduğu belirlenmişti. Bu nedenle Hatemi-J (2012) testinde de bu değerler esas alınmıştır. Hatemi-J (2012) testindeki ikinci aşama ise aralarında nedensellik ilişkisi aranan değişkenlerden oluşan modelin hata teriminin çoklu normal dağılmama ve çoklu $A R C H$ etkisi sorunlarını içerip içermediğinin test edilmesidir. Çünkü, Hatemi-J (2012) testi çoklu normal dağılmama ve çoklu ARCH etkisine karşı dirençli kritik tablo değerleri üretebilmektedir. Bu nedenle Hatemi-J'nin (2012) çalışmasında olduğu gibi ilgili bileşenlerin hata terimlerinde çoklu ARCH etkisi olup olmadığı
Hacker ve Hatemi-J (2006) testi ile hata terimlerinin çoklu normal dağılıma uyup uymadığı ise Doornik ve Hansen (2008) testi ile incelenmiştir. Bu kapsamda elde edilen sonuçlar Tablo 7'de sunulmuştur. Sonuçlar incelendiğinde aralarında asimetrik nedensellik ilişkisi aranacak bileşenlerden oluşan modellerin hata terimlerinin toplam 12 durumdan 10 tanesinde hem çoklu normal dağılıma uymadığı hem de çoklu ARCH etkisi taşıdığı görülmektedir. Kalan 2 durumda ise hata terimlerinin çoklu normal dağılıma uymadığı anlaşılmaktadır. Bu nedenle de Hatemi-J (2012) asimetrik nedensellik testi kullanılırken bu sorunlara karşı dirençlikritiktablo değerlerinden yararlanılmıştır. Bu hususlar dikkate alınarak uygulanan Hatemi-J (2012) asimetrik nedensellik testi sonuçları Tablo 8'de sunulmuştur. Sonuçlar incelendiğinde ABD dolarının değer kaybetmesinin tarımsal emtialar, yakıt ve ham petrol fiyatlarında artışa yol açtığı fakat bu durumun gıda, içecek ve metal fiyatları için geçerli olmadığı anlaşılmaktadır.

Tablo 7: Çoklu Normal Dağılım ve ARCH Testi Sonuçları

\begin{tabular}{|c|c|c|c|c|}
\hline \multirow[b]{2}{*}{ rfd(pc)-rbrd(nc) } & \multirow{2}{*}{$\begin{array}{l}\text { Gecikme } \\
\text { (VAR) } \\
2\end{array}$} & \multicolumn{2}{|c|}{$\begin{array}{l}\text { Hacker ve Hatemi-J (2006) testi } \\
\text { ARCH(1) ARCH(4) }\end{array}$} & \multirow{2}{*}{$\begin{array}{l}\text { Doornik ve Hansen testi } \\
75.35^{*}(0.000) \\
\end{array}$} \\
\hline & & 0.1100 & 0.3460 & \\
\hline rbvr(pc)-rbrd(nc) & 2 & 0.2960 & 0.5600 & $100.59 *(0.000)$ \\
\hline $\operatorname{ragrc}(p c)-r b r d(n c)$ & 2 & $0.096 * * *$ & $0.0120^{* *}$ & $21.55^{*}(0.000)$ \\
\hline rmtl(pc)-rbrd(nc) & 2 & $0.0120^{* *}$ & $0.0240 * *$ & $79.67^{*}(0.000)$ \\
\hline rfuel(pc)-rbrd(nc) & 1 & $0.0160^{* *}$ & 0.1020 & $208.57^{*}(0.000)$ \\
\hline roil(pc)-rbrd(nc) & 1 & $0.0240^{* *}$ & $0.0900^{* * *}$ & $225.52 *(0.000)$ \\
\hline rfd(nc)-rbrd(pc) & 2 & $0.0500^{* *}$ & $0.0300^{* *}$ & $35.516 *(0.000)$ \\
\hline $\operatorname{rbvr}(n c)-b r d(p c)$ & 2 & 0.1220 & $0.0580^{* * *}$ & $94.775 *(0.000)$ \\
\hline $\operatorname{ragrc}(n c)-r b r d(p c)$ & 3 & $0.0900^{* * *}$ & $0.0020^{*}$ & $34.250 *(0.000)$ \\
\hline rmtl(nc)-rbrd(pc) & 2 & $0.0860^{* * *}$ & $0.0540^{* * *}$ & $107.59 *(0.000)$ \\
\hline rfuel(nc)-rbrd(pc) & 2 & 0.1400 & $0.0280 * *$ & $33.853 *(0.000)$ \\
\hline $\operatorname{roil}(\mathrm{nc})-\mathrm{rbrd}(\mathrm{pc})$ & 2 & $0.0820 * * *$ & $0.0320^{* *}$ & $64.91 *(0.000)$ \\
\hline
\end{tabular}

****** sırasıyla \%1, \%5 ve \%10 anlamlılık düzeyini göstermektedir. Doornik ve Hansen (2008) testi için parantez içinde gösterilen değerler olasılık değerleridir. Hata terimlerinin elde edilmesi amacıyla kullanılan VAR modelinde gecikme uzunluğu HJC kriteri ile belirlenmiştir. pc pozitif, nc negatif bileşenleri göstermektedir. 
Tablo 8: Hatemi-J (2012) Asimetrik Nedensellik Testi Sonuçları

\begin{tabular}{|c|c|c|c|c|c|}
\hline & Wstat & \multicolumn{3}{|c|}{ Kritik değerler } & \multirow{2}{*}{\begin{tabular}{|l|}
$\begin{array}{l}\text { Gecikme uzunluğu } \\
\text { (HJC) }\end{array}$ \\
2 \\
\end{tabular}} \\
\hline $\mathrm{USD}^{--} \rightarrow \mathrm{RFD}^{++}$ & 2.534 & 9.623 & 6.375 & 4.908 & \\
\hline USD $^{-} \rightarrow \mathrm{RBVR}^{++}$ & 2.194 & 9.988 & 6.177 & 4.873 & 2 \\
\hline USD $^{--} \rightarrow$ RAGR $^{++}$ & $6.809 * *$ & 9.757 & 6.016 & 4.703 & 2 \\
\hline USD $^{--} \rightarrow \mathrm{RMTL}^{++}$ & 0.572 & 10.615 & 6.407 & 4.842 & 2 \\
\hline USD $^{-} \rightarrow$ RFUEL $^{++}$ & $5.608^{* *}$ & 6.751 & 4.094 & 2.829 & 1 \\
\hline $\mathrm{USD}^{-} \rightarrow \mathrm{ROIL}^{++}$ & $5.163^{* *}$ & 6.633 & 3.915 & 2.647 & 1 \\
\hline $\mathrm{USD}^{++} \rightarrow \mathrm{RFD}^{-}$ & $5.144^{* * *}$ & 10.159 & 5.950 & 4.558 & 2 \\
\hline $\mathrm{USD}^{++} \rightarrow \mathrm{RBVR}^{-}$ & $8.388^{*}$ & 9.532 & 6.000 & 4.538 & 2 \\
\hline $\mathrm{USD}^{++} \rightarrow \mathrm{RAGR}^{--}$ & $39.032^{*}$ & 12.344 & 8.073 & 6.174 & 3 \\
\hline $\mathrm{USD}^{++} \rightarrow \mathrm{RMTL}^{-}$ & $17.664^{*}$ & 11.368 & 6.373 & 4.834 & 2 \\
\hline $\mathrm{USD}^{++} \rightarrow \mathrm{RFUEL}^{-}$ & $24.980^{*}$ & 9.403 & 5.718 & 4.515 & 2 \\
\hline $\mathrm{USD}^{++} \rightarrow \mathrm{ROIL}^{-}$ & $29.094^{*}$ & 9.255 & 5.734 & 4.596 & 2 \\
\hline
\end{tabular}

" $\rightarrow$ " işareti birinci değişkenin ikinci değişkenin nedeni olmadığını ifade etmektedir. "-" ve "+" işaretleri asimetrik nedensellik ilişkisini temsil edecek şekilde sırasıyla değişkenlerdeki azalış ve artışı temsil etmektedir. Bu kapsamda örneğin, "USD"- $\rightarrow$ RFD ${ }^{-\prime}$ ifadesi ABD dolarındaki değer kaybının gıda emtialardaki fiyat düşüşünün nedeni olmadığını ifade eden Ho hipotezini ifade etmektedir. *, ****** sırasıyla \%1, \%5 ve \%10 anlamlılık düzeyini göstermektedir. Kritik tablo değerleri elde edilirken bootstrap 1000 alınmıștır. Maksimum gecikme uzunluğu 12 olacak şekilde optimal gecikme HJC ile belirlenmiştir. dmax 1 alınmıştır. RFD, RBVR, RMTL, RFUEL, ROIL ve RAGRC sırasıyla gıda, içecek, metal, yakıt, petrol ve tarımsal emtiaları, USD ise reel efektif döviz kurunu göstermektedir.

ABD dolarındaki değer kazancının etkilerine gelince, bu durumun inceleme kapsamındaki tüm emtiaların fiyatlarının düşmesine neden olduğu anlaşılmaktadır. Dolayısıyla, mevcut bulgular $A B D$ dolarının değer kazanmasının emtia fiyatları üzerindeki etkisinin değer kaybettiği duruma göre daha fazla olduğuna işaret etmektedir. Fakat, bu aşamaya kadar belirtilen Hatemi-J (2012) asimetrik nedensellik testinde gecikme uzunluğu Hatemi-J
(2012) tarafından geliştirilen ve yeni bir kriter olan HJC kriteri ile belirlenmiştir. Hem yeni bir kriter olması hem de literatürde genel olarak nedensellik testlerinin gecikme uzunluğuna duyarlı olduğunun ifade edilmesi nedeniyle çalışmanın bu aşamasında gecikme uzunluğunun belirlenmesinde AIC kriteri dikkate alınarak Hatemi-J (2012) testi yinelenmiştir. Bu kapsamda elde edilen bulgular Tablo 9'da sunulmuştur.

Tablo 9: Hatemi-J (2012) Asimetrik Nedensellik Testi Sonuçları

\begin{tabular}{|c|c|c|c|c|c|}
\hline & Wstat & $\begin{array}{lr}\text { Kritik değerler } \\
\% 1\end{array}$ & $\% 10$ & & $\begin{array}{l}\text { Gecikme } \\
\text { uzunluğu (AIC) }\end{array}$ \\
\hline $\mathrm{USD}^{-} \rightarrow \mathrm{RFD}^{++}$ & 2.534 & 9.623 & 6.375 & 4.908 & 2 \\
\hline USD $^{-} \rightarrow \mathrm{RBVR}^{++}$ & 5.196 & 11.533 & 8.009 & 6.246 & 3 \\
\hline USD $^{-} \rightarrow$ RAGR $^{++}$ & $13.546^{* *}$ & 15.799 & 10.393 & 8.748 & 4 \\
\hline USD $^{--} \rightarrow \mathrm{RMTL}^{++}$ & 0.572 & 10.615 & 6.407 & 4.842 & 2 \\
\hline USD $^{--} \rightarrow$ RFUEL $^{++}$ & $6.470^{* *}$ & 9.859 & 5.916 & 4.662 & 2 \\
\hline USD $^{-} \rightarrow \mathrm{ROIL}^{++}$ & $5.605^{* * *}$ & 9.480 & 5.890 & 4.533 & 2 \\
\hline $\mathrm{USD}^{++} \rightarrow \mathrm{RFD}^{-}$ & $5.144^{* * *}$ & 10.159 & 5.950 & 4.558 & 2 \\
\hline USD $^{++} \rightarrow$ RBVR $^{-}$ & $8.388^{*}$ & 9.532 & 6.000 & 4.538 & 2 \\
\hline USD $^{++} \rightarrow$ RAGR $^{-}$ & $40.632^{*}$ & 16.135 & 10.462 & 8.179 & 4 \\
\hline $\mathrm{USD}^{++} \rightarrow \mathrm{RMTL}^{-}$ & $17.664^{*}$ & 11.368 & 6.373 & 4.834 & 2 \\
\hline $\mathrm{USD}^{++} \rightarrow \mathrm{RFUEL}^{-}$ & $24.980^{*}$ & 9.403 & 5.718 & 4.515 & 2 \\
\hline $\mathrm{USD}^{++} \rightarrow \mathrm{ROIL}^{-}$ & $28.719^{*}$ & 12.583 & 8.154 & 6.590 & 3 \\
\hline
\end{tabular}

Tablo ile ilgili açıklamalar Tablo 9'daki gibidir. 
Sonuçlar incelendiğinde bulguların HJC kriterinin kullanıldığı durumda elde edilen sonuçlarla aynı olduğu görülmektedir. Bu da elde edilen nedensellik testi sonuçlarının güvenilirliğini artırmaktadır.

\section{SONUÇ}

$\mathrm{Bu}$ çalışmada emtia piyasalarındaki fiyat hareketlerinin açıklanmasında $A B D$ dolarının küresel bazdaki değeri üzerinde durulmuştur. $A B D$ dolarını temsilen geniş tanımlı reel efektif $A B D$ dolar endeksi (Broad dollar index) kullanılmıştır. Emtia olarak IMF tarafından yayınlanan gıda, içecek, metal, yakıt, petrol ve tarımsal emtia fiyat endekslerinden yararlanılmıştır. Çalışma bulguları ABD doları ile gıda, yakıt ve petrol emtiaları arasında ters yönlü uzun dönemli bir ilişki olduğuna işaret etmektedir. Uzun dönemde $A B D$ dolarının \%1 değer kazanmasının ilgili emtiaların fiyatında sırasıyla $\% 0.44, \% 1$ ve $\% 1.3^{\prime}$ lük bir azalışa yol açtığı görülmektedir. ABD doları ile metal, içecek ve tarımsal emtia endeksleri arasında ise herhangi bir uzun dönemli ilişkiye rastlanmamıştır. Dolayısıyla, uzun dönemde ABD dolarındaki fiyat hareketlerinin daha çok enerji (yakıt ve petrol) emtiaları üzerinde etkili olduğu anlaşılmaktadır. Kısa dönemli ilişki analizi sonuçlarına bakıldığında ise Hatemi-J (2012) asimetrik nedensellik testi sonuçlarına göre ABD dolarının değer kaybetmesi sadece yakıt, ham petrol ve tarımsal emtia fiyatlarının yükselmesine yol açarken $A B D$ dolarının değer kazanması inceleme kapsamındaki tüm emtiaların fiyatlarının düşmesine yol açmaktadır. Dolayısıyla, kısa dönemde ABD dolarının değer kaybetmesinden ziyade değer kazanmasının emtia fiyatları üzerinde daha fazla etkili olduğu anlaşılmaktadır. Mevcut bulguların öncelikle emtia piyasalarında yaşanan fiyat hareketlerinin ve bu fiyat hareketlerinde $A B D$ dolarının etkisinin anlaşılması açısından önemli olduğu düşünülmektedir. Ayrıca, ABD merkez bankası FED'in sıkılaştırıcı para politikası adımlarının ABD dolarının küresel bazda değer kazanmasına yol açabileceği de bilinmektedir. Bu da emtia fiyatları üzerinde düşüş yönünde bir baskı yaratmaktadır. Dolayısıyla, mevcut konjonktürde ihracatlarında emtiaların önemli yer tuttuğu ekonomilerin bu durumu dikkate alan ekonomi politikaları uygulamalarının önemli olduğu düşünülmektedir. Dahası, ABD doları ile emtialar arasında tespit edilen nedensellik ilişkisinin yatırımcılar için de önemli bilgiler içerdiği düşünülmektedir. Çünkü, bulgular özellikle $A B D$ dolarının değer kazanmasının emtia fiyatlarının düşmesine yol açtığını ifade etmekteydi. Dolayısıyla, yatırımcılar ABD dolarındaki fiyat hareketlerine bakarak önceden emtia fiyatlarının seyri konusunda bilgi sahibi olabilirler.

\section{SON NOTLAR}

'Ayrıntılı bilgi için bakınız: www.imf.org/external/np/ res/commodity.

${ }^{2}$ Maki (2012) koentegrasyon testi sabit terim ve trend gibi bileşenlerde de çoklu yapısal kırılmalara izin verebilmektedir. Fakat, buradaki amaç ABD dolarının etkisinin incelenmesi olduğundan çalışmada rejim değişim modeli üzerinde durulmuştur. Bir diğer ifade ile sabit terim ve eğim parametrelerinde birlikte çoklu yapısal kırılmaların söz konusu olduğu model spesifikasyonu dikkate alınmıştır.

${ }^{3}$ Yer kısıtı nedeniyle sonuçlar burada gösterilmemiştir. Talep edilmesi halinde yazardan temin edilebilir.

${ }^{4}$ Yer kısıtı nedeniyle grafikler burada gösterilmemiştir. Talep edilmesi halinde yazardan temin edilebilir.

${ }^{5}$ Maki'nin (2012) orijinal makalesinde küçük bir hata bulunmaktadır. Maki'nin (2012) çeşitli model spesifikasyonlarının kritik tablo değerlerini verdiği sayfa 2013'teki tabloda modellerin sıralanışı yanlıştır. Doğru sıralanış model $0,1,2$ ve 3 için sırasıyla $C$, $C / T, C / S$ ve $C / S / T$ şeklinde olmalıdır. Aksi takdirde model spesifikasyonları için tablodan yanlış kritik değerler seçilmektedir. Bu durum sayın Maki'ye de bildirilmiş ve belirttiğimiz hususun doğru olduğu sayın Maki tarafından da kabul edilmiştir. Dolayısıyla bu çalışmada rejim değişim modeli (C/S) için kritik değerler bu sıralama dikkate alınarak belirlenmiştir. 


\section{KAYNAKLAR}

Akram,Q.F. (2008) "Commodity Prices, Interest Rates and the Dollar", Energy Economics, 31: 838-851

Baffes, J. (2007) "Oil Spills on other Commodities", Resources Policy, 32: 126-134.

Bai, J. ve Perron, P. (1998) "Estimating and Testing Linear Models with Multiple Structural Changes", Econometrica, 66 (1): 47-78.

Bai, J. ve Perron, P. (2003) "Computition and Analysis of Multiple Structural Change Models", Journal of Applied Econometrics, 18 (1): 1-22.

Basher, S.A., Haug, A.A. ve Sadorsky, P. (2016) "The impact of Oil Shocks on Exchange Rates: A MarkovSwitching Approach, Energy Economics, 54: 11-23.

Beckmann, J. ve Czudaj, R. (2013) "Oil Prices and Effective Dollar Exchange Rates", International Review of Economics and Finance, 27: 621-636.

Bloomberg, S.B. ve Harris, E.S.(1995) "The Commodity Consumer Prices Connection: Fact or Fable ?", Federal Reserve Bank of New York Economic Policy Review, 3: 21-38.

Borensztein, E. ve Reinhart, C.M. (1994) "The Macroeconomic Determinants of Commodityprices", IMF Staff Papers, 41: 236-261.

Carrion-i Silvestre, J.L., Kim, D. ve Perron, P. (2009) " GLS-based Unit Root Tests with Multiple Structural Breaks under both Null and Alternative Hypotheses", Econometric Theory, 25 (6): 1754-1792.

Chen, H., Liu, L., Wang,Y. ve Zhu,Y. (2016) "Oil Price Shocks and U.S. Dollar Exchange Rates", Energy, 112: 1036-1048.

Coudert, V., Couharde, C. ve Mignon, V. (2013) "On the Impact of Oil Price Volatility on the Real Exchange Rate-Terms of Trade Nexus: Revisiting Commodity Currencies, CEPII Working Paper, No: 40 December..

Doornik, J.A. ve Hansen, H. (2008) "An Omnibus Test for Univariate and Multivariate Normality", Oxford Bulletion of Economics and Statistics, 70: 927-939.

Druck,P., Magud, N.S. ve Mariscal, R.(2015) “ Collateral Damage: Dollar Strength and Emerging Markets' Growth", IMF Working Paper, No. 15/179.

Engle, R.F. ve Granger, C.W.J. (1987) "Cointegration and Error Correction: Representation, Estimation and Testing", Econometrica, 55: 251-276.

Fan, Y.ve Xu, J.H. (2011) "What has Driven Oil Prices since 2000 ? A Structural Change Perspective" Energy Economics, 33: 1082-1094.

Frank, J. ve Garcia, P. (2010) "How Strong are the Linkages among Agricultural, Oil, and Exchange Rate
Markets?" Proceedings of the NCCC- 134 Conference on Applied Commodity Price Analysis, Forecasting, and Market Risk Management. St. Louis, MO. [http:// www.farmdoc.illinois.edu/nccc134].

Gilbert, C.L. (1989) "The Impact of Exchange Rates and Developing Country Debt on Commodity Prices", Economic Journal, 99: 773-783.

Golub, S.S. (1983) "Oil Prices and Exchange Rates", The Economic Journal, 93 (371): 576-593.

Hacker, R.S. ve Hatemi-J, A. (2005) “ A Multivariate Test for ARCH Effects", Applied Economic Letters, 12:411417.

Hamilton, J.D. (2008) " Understanding Crude Oil Prices", Energy Journal, 30: 179-206.

Hatemi, J.A. (2012) "Asymmetric Causality Tests with an Application", Empirical Economics, 43(1) : 1447-456.

Holtham, G.H. (1988) "Modeling Commodity Prices in a World Macroeconomic Model", In:Guvenen, O. (Ed.), International Commodity Market Models and Policy Analysis, Kluwer Academic Publishers, Boston

Hussain, M., Zebende, G.F., Bashir, U. ve Donghonga, D. (2017) “Oil Price and Exchange Rate Co-Movements in Asian Countries: Detrended Cross-Correlation Approach", Physica A, 465: 338-346.

IMF,World Economic Outlook, April 2008, "Housing and the Business Cycle", https://www.imf.org/ external/pubs/ft/weo/2008/01/pdf/text.pdf (02.11.2016)

Ji, Q. ve Fan,Y. (2012) " How does Oil Price Volatility Affect Non-Energy Commodity Markets ? " Applied Energy, 89: 273-280.

Jiang, J. ve Gu, R. (2016) "Asymmetrical Long-Run Dependence between Oil Price and US Dollar Exchange Rate-based on Structural Oil Shocks", Physica A, 456: 75-89.

Johansen, S. (1988) "Statistical Analysis of Cointegration Vectors", Journal of Economic Dynamics and Control, 12(2-3) : 231-254.

Krugman, P. (1983) "Oil and the Dollar in Economic Interdependence and Flexible Exchange Rates", the National Bureau of Economic Research Working Paper No: 554, MIT Press, Cambridge.

Lim, E.G. (2006) “The Euro's Challenge to the Dollar: Different Views from Economists and Evidence from COFER (Currency Composition of Foreign Exchange Reserves) and Other Data", IMF Working Paper, WP/ 06/153.

Lin, F.L., Chen, Y.F. ve Yang, S.Y. (2016) “Does the Value of US Dollar matter with the Price of Oil and Gold? 
A Dynamic Analysis from Time-Frequency Space", International Review of Economics and Finance, 43, 59-71.

Maki, D. (2012) "Tests for Cointegration Allowing for an Unknown Numberof Breaks", Economic Modelling, 29 : 2011-2015.

Nazlioglu, S. ve Soytas, U. (2012) "Oil Price, Agricultural Commodity Prices, and the Dollar: A Panel Cointegration and Causality Analysis", Energy Economics, 34: 1098-1104.

Phillips, P. C. B. ve Perron, P. (1988) "Testing for a Unit Root in Time Series Regression", Biometrica, 75 (:) 346-335.

Reboredo, J.C. ve Ugando, M. (2014) "US Dollar Exchange Rate and Food Price Dependence:
Implications for Portfolio Risk Management", North American Journal of Economics and Finance, 30: 72-89

Sari,R., Hammoudeh, S. ve Soytas, U. (2010) “Dynamics of Oil Price, Precious Metal Prices, and Exchange Rate" Energy Economics, 32: 351-362.

Truchis, G. ve Keddad, B. (2016) "On the Risk Comovements between the Crude Oil Market and U.S. Dollar Exchange Rates", Economic Modelling, 52, 206-215.

Zhang, Y. (2013) "The Links between the Price of Oil and the Value of US Dollar", International Journal of Energy Economics and Policy, 3(4):341-351

Zhang, Y.J., Fan, Y. , Tsai, H.T. ve Wei, Y.M . (2008) "Spillover Effect of US Dollar Exchange Rate on Oil Prices", Journal of Policy Modeling, 30 (6): 973-991. 